\title{
Cost-Effectiveness Analysis Of Plant Versus Antibiotic Regimens In Treating Patients With Helicobacter Pylori (H. Pylori) Infection In The South Of Iran
}

\section{Hossein Faramarzi}

Shiraz University of Medical Sciences

\section{Zahra Khajoei}

Shiraz University of Medical Sciences

\section{Farhad Lotfi}

Shiraz University of Medical Sciences

\section{Mehdi Rezaee}

Kerman University of Medical Sciences

\section{Mehrnoosh Emadi}

Shiraz University of Medical Sciences

Khosro Keshavarz ( $\sim$ khkeshavarz@sums.ac.ir)

Shiraz University of Medical Sciences

\section{Research Article}

Keywords: Cost-Effectiveness, Economic Evaluation, Helicobacter pylori, Antibiotic, plant

Posted Date: February 28th, 2022

DOI: https://doi.org/10.21203/rs.3.rs-1377344/v1

License: (c) (i) This work is licensed under a Creative Commons Attribution 4.0 International License.

Read Full License 


\section{Abstract}

Background: Helicobacter pylori infection is highly prevalent worldwide and affects more than half of the world's population. A variety of treatment regimens to eliminate $\mathrm{H}$. pylori infection have been evaluated, but choosing the best treatment method that results in the most eradication at the lowest cost is one of the challenges facing physicians. Therefore, the present study aimed at analyzing the cost-effectiveness of using different methods to treat $\mathrm{H}$. pylori in southern Iran.

Methods: This study was a cost-effectiveness analysis conducted on 132 patients with $\mathrm{H}$. pylori who referred to Shahid Motahari Clinic in Shiraz. The study was carried out in 2020 to evaluate two drug treatment strategies, including antibiotics (pantoprazole $40 \mathrm{mg}$, Bismuth subcitrate $108 \mathrm{mg}$, tetracycline $500 \mathrm{mg}$, and metronidazole 200 and $400 \mathrm{mg}$ ) and plants (Supermint Barij soft capsules $20 \mathrm{mg}$, Alium S garlic tablets $400 \mathrm{mg}$, and Green Teadin (green tea) tablets $500 \mathrm{mg}$ ). The patients were randomly divided into two groups, 64 of whom received an antibiotic regimen and 68 patients given a plant regimen. The success rate of clinical trials in each treatment method was determined as the clinical outcome. This study was conducted from a community perspective and therefore, direct and indirect costs were included. A data collection form was also used to collect the cost and effectiveness data. In addition, a one-way sensitivity analysis was performed to measure the robustness of the results. The data were analyzed using TreeAge Pro 2011 and Excel 2016 software.

Results: The results showed that antibiotic treatment was cheaper and more effective than plant treatment and was the dominant strategy. The mean costs in the antibiotics and plant groups were $\$ 446.14$ and $\$ 477.81$, respectively, and the effectiveness was $0.625 \%$ and $0.382 \%$. In addition, the oneway sensitivity analysis confirmed the robustness of the study results.

Conclusion: The results showed that the use of antibiotics was a cost-effective and dominant strategy compared to plant treatment and could be suggested as a better alternative to a wide range of patients with Helicobacter pylori infection.

\section{Introduction}

Helicobacter pylori $(\mathrm{H}$. pylori) is the most common bacterial infection worldwide[1], the prevalence of which among adults in developed countries is $20-40 \%[2,3]$. However, the infection rate reaches $90 \%$ in the first 5 years of life in developing countries[4]. As the most common infectious agent, H. pylori is involved in a variety of common gastrointestinal disorders including gastritis, duodenal ulcer, peptic ulcer, adenocarcinoma, and gastric lymphoma[5], and is also involved in about $89 \%$ of non-cardiac gastric cancers in the world[6]. In addition, it can lead to many diseases of non-digestive origin, such as cardiovascular disease, autoimmunity, Parkinson's, obesity, and allergic disorders[7]. Therefore, preventing or eradicating bacterial infections can help avoid these diseases.

Nowadays, the biggest challenge in eradicating H. pylori infection is the low tolerance of patients for medical treatments, antibiotic resistance and side effects, and the high cost of antibiotic treatment[8]. 
Various treatment regimens containing several antimicrobial compounds have already been examined to eliminate $\mathrm{H}$. pylori infection[9-11]. The failure of single drug methods has led to the development of drug regimens with a combination of three or four drugs, the most common of which is triple therapy. This treatment regimen includes a proton pump or inhibitor bismuth and two antibiotics, i.e. amoxicillin and clarithromycin[12,13]. Early studies suggested that eradication with triple therapy was cost-effective, and resistance to some strains was seen in more than $50 \%$ of the patients. However, triple therapy has shown a gradual decrease in efficacy (eradication rate of $<80 \%$ ) in recent years[14]. It also has side effects such as metallic taste in the mouth, increased sensitivity to light, constipation, and diarrhea[15]. The use of a four-drug regimen containing omeprazole, bismuth, and two antibiotics (Metronidazole and Tetracycline) was associated with $80 \%$ eradication and was recommended as a first-line treatment in areas with high resistance (over 15\%) to Metronidazole and Clarithromycin in the patients who did not respond to the three-drug regimen containing Metronidazole or Clarithromycin[16, 17]. The four-drug regimen is not only very expensive [14]but in many cases leads to treatment discontinuation before the end of the treatment course due to the complications such as seizures and polyneuropathy in the patients who use metronidazole for a long time[18].

Despite various treatment methods, recurrence of the disease has been reported in a number of cases after treatment completion. Therefore, the use of plants and herbal medicines may be beneficial due to their numerous medicinal effects[19]. Today, the antimicrobial effects of many plant species (e.g. garlic) on $\mathrm{H}$. pylori infection have been investigated and proposed as a way of increasing the efficacy of $\mathrm{H}$. pylori treatment[20]. The results of a study showed that adding garlic extract to the standard anti-H. Pylori infection regimen increased its eradication rate from 52.6-75.8\%[21], and long-term consumption of garlic reduced the risk of gastric and colon cancers[22]. However, the results of a study by McNulty et al. did not show a significant relationship between garlic consumption and eradication of $\mathrm{H}$. pylori infection[23]. Thus, considering the high prevalence of gastrointestinal diseases in the world, especially gastric adenocarcinoma and its relationship with $\mathrm{H}$. pylori, choosing the best treatment method that causes the highest eradication rate at the lowest cost is one of the challenges facing physicians[24]. Therefore, the present study aimed to analyze the cost-effectiveness of using different H. Pylori treatment methods in Shahid Motahari Clinic in Shiraz in 2020.

\section{Methods Overview}

This prospective cost-effectiveness study was conducted on $132 \mathrm{H}$. pylori patients who referred to Shahid Motahari Clinic in Shiraz (referral clinic) in order to examine two drug treatment strategies including antibiotics and plants in 2020. The patients were randomly divided into two groups of receiving antibiotic $(n=64)$ and plant $(n=68)$ regimens. The antibiotic group was given a drug regimen including pantoprazole $40 \mathrm{mg}$ twice a day, bismuth subcitrate $108 \mathrm{mg}$ and tetracycline $500 \mathrm{mg} 4$ times a day, and metronidazole $200 \mathrm{mg}$ three times daily and $400 \mathrm{mg}$ once overnight for 14 days[15]. The plant receiving group was given Supermint Barij soft capsules 20 mg, Alium S garlic tablets 400 mg[25], and Green Teadin (green tea) tablets $500 \mathrm{mg}$ three times a day for 14 days[26]. 
A decision tree model was used to estimate the cost and effectiveness results. The cost data were collected from a community perspective, and direct and indirect costs were included in the study. The success rate of clinical trials in each treatment method was determined as the effectiveness outcome. A data collection form was also used to collect the cost and effectiveness data. The results were presented in the form of incremental cost-effectiveness ratio (ICER). Furthermore, the one-way sensitivity analysis was performed to measure the effects of parameter uncertainty in the model. The data were analyzed using TreeAge Pro 2011 and Excel 2016 software.

\section{Inclusion And Exclusion Criteria}

The inclusion criteria were as follows: the patients with dyspepsia who had a positive antigen stool test result; not taking antibiotics for at least 4 weeks before the start of the study; no history of allergies to mint, green tea, and garlic pills; and no use of other adjunctive therapy or medicinal plants for at least two weeks before the start of the study. The exclusion criteria were liver disease, gallstones or biliary obstruction, any gastrointestinal risk symptoms that required endoscopic examination (e.g., weight loss, anemia, severe gastrointestinal symptoms, recurrent vomiting, dysphagia, and gastrointestinal bleeding), not taking the drugs for at least one day, and not taking daily doses.

\section{Treatment Costs}

In this study, the costs were collected from a community perspective. Therefore, they included direct medical costs (DMCs), direct non-medical costs (DNMCs), and indirect costs (ICs).

The DMCs included the costs of medication, tests, doctor visits, and hospitalization, which would include the side effect cost of each treatment method and the use of a subsequent method in case of the failure of the initial treatment. The DMC data were collected from the patients' medical records as well as the opinions of clinical experts in this field.

The DNMCs included transportation costs (intra-city and intercity) as well as food and accommodation costs for the patient and companions to receive medical services.

The ICs also included the mean days of absence from work of the patients and companions and reduced productivity lost due to illness, disability, and death. The DNMC and IC data were collected based on the patients' self-report through face-to-face interviews or telephone calls. The human capital approach was used to calculate the IC[27, 28]. In addition, all costs were calculated based on the tariffs of 2020 and converted into international dollars (purchasing power parity (PPP)) at the exchange rate of 1 dollar = 22057 Rials[29].

\section{Model Structure}


Figure 1 shows a schematic diagram of the decision tree model for antibiotic versus plant treatment strategies. The success and failure of the drugs and their side effects were plotted for each strategy in order to select the best. In addition, the costs and effectiveness of each strategy were entered into the model separately.

Insert Fig. 1 here:

\section{Cost-effectiveness Analysis}

The model was designed in Tree-age software and the extracted data were entered into it. The costs, effectiveness, and cost-effectiveness of the two drugs were then calculated and their ICERs were estimated using the following equation.

$$
I C E R=\frac{\text { costplant }- \text { costAntibiotics }}{\text { Effectivenessplant }- \text { EffectivenessAntibiotics }}
$$

\section{Sensitivity Analysis}

The one-way sensitivity analysis was performed to investigate the effects of parameter uncertainty on the results. To this end, some key parameters such as cost and utility were changed by $20 \%$ for each drug strategy and the results were presented in the form of a Tornado Diagram. In addition, due to the lack of a cost-effectiveness threshold in Iran and as proposed by the World Health Organization (WHO), the threshold of one to three times the per capita GDP was considered for developing countries[30]. The GDP in Iran was \$ 12547 in 2019 (1* GDP)[31], using which the threshold of willingness to pay (WTP) was \$ $37641(3 *$ GDP) in the country[32].

\section{Results}

A total of 132 patients with H.pylori were included in the study. Table 1 provides descriptive results including the data on gender, age, employment status, and education. As shown in Table 2, DMCs accounted for the highest costs in both groups (\$204.18 PPP in antibiotic and \$210.47 PPP in plant treatments). On the other hand, the lowest costs were associated to indirect costs with an average value of $\$ 111.81$ PPP in the antibiotic and $\$ 119.83$ PPP in the plant methods. Overall, the mean total cost of antibiotic treatment (\$446.14 PPP) was lower than plant treatment (\$ 477.81 (PPP)). 
Table 1

Demographic variables among patients between two groups of plant and antibiotic

\begin{tabular}{|c|c|c|c|c|c|}
\hline \multirow[t]{2}{*}{ Variable } & & \multicolumn{2}{|l|}{ plant } & \multicolumn{2}{|l|}{ antibiotic } \\
\hline & & Number & Percent & Number & Percent \\
\hline \multirow[t]{3}{*}{ sex } & Female & 41 & 60.29 & 36 & 56.25 \\
\hline & Male & 27 & 39.71 & 28 & 43.75 \\
\hline & Total & 68 & 100 & 64 & 100 \\
\hline \multirow[t]{7}{*}{ Age (year) } & $20-30$ & 15 & 22.05 & 6 & 9.38 \\
\hline & $31-40$ & 21 & 30.88 & 24 & 37.5 \\
\hline & $41-50$ & 14 & 20.59 & 20 & 31.25 \\
\hline & $51-60$ & 10 & 14.71 & 12 & 18.75 \\
\hline & $61-70$ & 7 & 10.3 & 1 & 1.56 \\
\hline & $71-80$ & 1 & 1.47 & 1 & 1.56 \\
\hline & Total & 68 & 100 & 64 & 100 \\
\hline \multirow{6}{*}{$\begin{array}{l}\text { Patients } \\
\text { employment }\end{array}$} & unemployed & 35 & 51.5 & 34 & 53.13 \\
\hline & Employed & 2 & 3 & 5 & 7.81 \\
\hline & Self employed & 13 & 19.1 & 13 & 20.31 \\
\hline & Retired & 1 & 1.4 & 4 & 4.69 \\
\hline & Daily worker & 17 & 25 & 9 & 14.06 \\
\hline & Total & 68 & 100 & 64 & 100 \\
\hline \multirow[t]{7}{*}{ Patient Education } & Illiterate & 13 & 19.12 & 8 & 12.5 \\
\hline & Fifth elementary & 25 & 36.77 & 15 & 23.43 \\
\hline & High school drop-out & 9 & 13.23 & 7 & 10.94 \\
\hline & High school diploma & 10 & 14.7 & 18 & 28.13 \\
\hline & Two year collage degree & 3 & 4.41 & 5 & 7.81 \\
\hline & Bachelor degree & 8 & 11.77 & 11 & 17.19 \\
\hline & TOTAL & 68 & 100 & 64 & 100 \\
\hline
\end{tabular}


Table 2

Estimated mean Direct medical and non-medical costs, Indirect costs, and Total costs per patient by Dollar in plant and antibiotic groups

\begin{tabular}{|lllll|}
\hline Type of Service & \multicolumn{3}{c}{ Plant } & \multicolumn{3}{l|}{ Antibiotic } \\
\cline { 2 - 5 } & Mean & SD & Mean & SD \\
\hline Direct medical cost & & & & \\
\hline visit & 49.96 & 9.34 & 45.33 & 9.33 \\
\hline Drugs & 64.86 & 23.57 & 72.03 & 26.73 \\
\hline Tests & 95.18 & 17.8 & 86.35 & 17.79 \\
\hline Other services & 0.47 & 1.9 & 0.47 & 1.31 \\
\hline Total & 210.47 & 52.61 & 204.18 & 55.16 \\
\hline Direct non-medical cost & & & & \\
\hline Transport & 100.39 & 92.95 & 85.67 & 70 \\
\hline Foods & 30.4 & 40.88 & 29.37 & 39.46 \\
\hline Accommodation & 16.72 & 26.25 & 15.11 & 33.19 \\
\hline Total & 147.51 & 160.08 & 130.15 & 142.65 \\
\hline Indirect cost & & & & \\
\hline Time spent by the patient's accompany and patient & 119.83 & 67.39 & 111.81 & 58.62 \\
\hline Total cost & & & & \\
\hline Direct Medical Costs & 210.47 & 52.61 & 204.18 & 55.16 \\
\hline Direct Non-medical Costs & 147.51 & 160.08 & 130.15 & 142.65 \\
\hline Indirect Costs & 119.83 & 67.39 & 111.81 & 58.62 \\
\hline Total Costs & 477.81 & 280.08 & 446.14 & 256.43 \\
\hline
\end{tabular}

According to Table 3 and Fig. 2, the results of the cost-effectiveness analysis showed that the calculated effectiveness of antibiotic and plant strategies were $62.5 \%$ and $38.24 \%$, respectively, and the costs were $\$$ 446.14 and $\$ 457.81$ PPP, respectively. Thus, antibiotic treatment was less costly and more effective, and therefore, a more cost-effective option and a dominant strategy. 
Table 3

Comparison between cost and effectiveness in plant and antibiotic groups

\begin{tabular}{|llllll|}
\hline Strategy name & Effectiveness & Cost (PPP\$) & ICER & & \\
\hline Plant & 0.382 & -0.243 & 457.81 & 11.67 & -48.024 \\
\cline { 1 - 2 } & Antibiotic & 0.625 & & 446.14 & \\
\hline \\
\hline
\end{tabular}

\section{Uncertainty Analysis}

The effects of uncertainty were studied using the one-way sensitivity analysis, and the value of each variable changed by $20 \%$. Figure 3 presents the results of the one-way sensitivity analysis in the form of a tornado diagram. The changes in many parameters did not have significant effects on the study results. However, ICER had the highest sensitivity to plant cost and the lowest sensitivity to the effectiveness of plant treatment in the patients with H. pylori. In fact, plant price was a determining parameter in ICER for the patients with H.pylori.

\section{Discussion}

The present research is in fact the first economic evaluation study that compared the cost-effectiveness of using antibiotic and plant treatments in patients with $\mathrm{H}$. pylori in Iran. The results showed that antibiotic treatment was more cost-effective than plant treatment. Few studies have been conducted in this field. Using cost and effectiveness data to compare the cost-effectiveness of different $\mathrm{H}$. pylori eradication regimens in the patients with gastric ulcer or chronic gastritis, Sancar et al (2006) concluded that the use of a 4-drug regimen was more cost-effective than other treatment regimens, and the eradication rate and cost-effectiveness ratio for the 4-drug treatment was $90 \%$ ( $€ 158.7$ )[33], confirming the results of the present study. In contrast, Yousef-Nezhad et al. (2017) showed that H. pylori treatment with alternative therapies using herbal compounds had less toxicity and side effects and was more costeffective and less costly than drug treatments[34]. Bokaeian et al (2013) also showed that the use of medicinal plants was cheaper than chemical drugs and easily accessible[35]. This is inconsistent with the results of the present study.

In this study, using the antibiotic regimen including four types of antibiotics (pantoprazole, bismuth, tetracycline, and metronidazole) (0.625) was more effective than using the plant regimen (0.382).

The results of the studies by Jun-Ling Ma et al. (2012) and Wei-cheng et al (2006) in China showed that treatment with amoxicillin and omeprazole reduced the incidence of $\mathrm{H}$. pylori infection and gastric cancer by $39 \%$, but long-term use of garlic and vitamins was not associated with a statistically significant 
reduction in the incidence of $\mathrm{H}$. pylori infection and gastric cancer mortality [36, 37]. Kaviani et al. (2001) in Iran examined the two-week treatment with amoxicillin, metronidazole, bismuth, and ranitidine to eradicate Helicobacter pylori and reported $73 \%$ of effectiveness[38]. The results of a study by Nijevitch et al. (2007) in Russia indicated that a triple-therapy including bismuth subcitrate, nifuratel, and amoxicillin was $86 \%$ successful in eradicating $\mathrm{H}$. pylori infection in childhood[39]. Hojo et al. (2001) stated that eradication rate of Helicobacter pylori with a drug regimen containing amoxicillin, metronidazole, bismuth, and omeprazole was 39\%[40]. A study carried out by Tireno et al. in 1999 reported $75 \%$ potency of omeprazole, amoxicillin, and clarithromycin in eradicating Helicobacter pylori during two weeks[41].

The results of the study by Rahimian et al. (2013) in Shahrekord suggested that the combination of garlic and peppermint extracts, in comparison with metronidazole, was unsuccessful in eradicating $\mathrm{H}$. pylori infection, and metronidazole could still be used as an effective drug in the treatment of the disease[25]. Graham et al. (1999) in the United States showed that the use of herbal medicines such as garlic and pepper had no effect on Helicobacter pylori compared to a drug regimen such as bismuth[42].

The ineffectiveness of plant regimens and the use of garlic in the treatment of the patients with $\mathrm{H}$. pylori infection was stated in other studies [23, 42-44]. In contrast, the results of the study by Nagata et al. (2017) in China indicated the effectiveness of goshuyuto and the successful eradication of a resistant species of $\mathrm{H}$. pylori infection with this medicinal plant compared to drug regimens[31]. Besides, Hajiagha mohammadi et al. (2015) in Qazvin stated that adding garlic extract to the standard anti-H. pylori regimen increased its eradication rate from 52.6-75.8\%[21]. Some other studies also indicated the effectiveness of plant regimens, especially garlic extract and green tea alone or in combination with other treatments such as proton pump inhibitors and antibiotics in the real stomach environment [24, 45-48], which are not in line with the results of this study.

According to the results of the one-way sensitivity analysis, the ICER was negative and the highest sensitivity was to the cost of the plant regimen, but considering that in the cost-effectiveness sensitivity analysis the ICER remained negative, it could be said that the results of the study were robust enough. Therefore, the results showed that the sensitivity analysis did not change the status of the antibiotic regimen as the most effective treatment, and this is a sign of the robustness of the study results.

One strength of this study is the inclusion of total costs, including DMCs, DNMCs, and ICs. In addition, this is the first economic evaluation study in Iran addressing the cost-effectiveness of using antibiotic and plant treatment methods in patients with H.pylori. Among the limitations of this study are the relatively small sample size and the possibility or impossibility of generalizing the results to other geographical areas.

\section{Conclusion}

According to the results of this study, antibiotic treatment was a cost-effective strategy compared to plant treatment and could be suggested as a good alternative to a wide range of patients with $\mathrm{H}$. pylori infection. It could also be used as the first priority for the treatment of the patients in the country. 


\section{List Of Abbreviations}

H. pylori: Helicobacter pylori, ICER: Incremental Cost-Effectiveness Ratio, DMC: Direct Medical Costs, DNMC: Direct Non-Medical Costs, IC: Indirect Costs, WHO: World Health Organization, PPP: Purchasing Power Parity, GDP: Gross Domestic Product, PSA: Probabilistic Sensitivity Analysis, WTP: Willingness to Pay

\section{Declarations}

\section{Ethics approval and consent to participate}

All data are collected and handled in accordance with the relevant privacy protection guidelines. According to Iran law, the study did not fall under the remit of the Medical Research Involving Human Subjects Act and no approval by a medical ethics committee was necessary. Verbal consent was obtained from respondents who completed a questionnaire anonymously, and their response expressed their willingness to participate. Written consent was obtained from participants to the cognitive interviews

\section{Consent for publication:}

All participants completed a consent form, stating that they were well-informed about the Content of questionnaires and that they agreed upon the publication of anonymized data.

\section{Availability of data and material:}

The data used in this study are not publicly available because the participants were promised that the raw data would remain confidential. However, they are available from the corresponding author on reasonable request.

\section{Competing interests:}

The authors declare that there is no conflict of interest regarding the publication of this paper.

\section{Funding:}

This research was supported by Shiraz University of Medical Sciences (Iran) through grant No 1323 and was approved by the ethics committee with the code of IR.SUMS.REC.1398.1323. The funder had no role in the design and conduct of the study, collection, management, analysis, and interpretation of the data, preparation, review, or approval of the manuscript, and decision to submit the manuscript for publication.

\section{Authors' contributions:}

Conception and design: H.F., Z.Kh., F.L., M.E., Kh.K.; Material preparation and data collection: H.F., Z.Kh., F.L., M.R., M.E, Kh.K. ; Data analysis: Z.Kh.; Interpretation of data: H.F., Z.Kh., F.L., M.R., M.E, Kh.K; The frst 
draft of the manuscript was written by M.E.; Supervision: Kh.K. All authors read and approved the fnal manuscript.

\section{Acknowledgements:}

The researchers would like to thank Shiraz University of Medical Sciences, especially Shahid Motahari Clinic and thank the studied patients for their kind cooperation with the researchers in collecting data.

\section{References}

1. Hekmatdoost, A., et al., The effect of garlic consumption on Helicobacter pylori treatment using urea breath test: a randomized clinical trial. Journal of Nutritional Sciences and Dietetics, 2015: p. 21-27.

2. Fennerty, M.B., Helicobacter pylori: why it still matters in 2005. Cleveland Clinic journal of medicine, 2005. 72: p. S1-7; discussion S14.

3. Suerbaum, S. and P. Michetti, Helicobacter pylori infection. New England Journal of Medicine, 2002. 347(15): p. 1175-1186.

4. Adamek, R., et al., Primary and acquired Helicobacter pylori resistance to clarithromycin, metronidazole, and amoxicillin-influence on treatment outcome. The American journal of gastroenterology, 1998. 93(3): p. 386-389.

5. Picoli, S.U., et al., Resistance to amoxicillin, clarithromycin and ciprofloxacin of Helicobacter pylori isolated from Southern Brazil patients. Revista do Instituto de Medicina Tropical de São Paulo, 2014. 56(3): p. 197-200.

6. Plummer, M., et al., Global burden of gastric cancer attributable to Helicobacter pylori. International journal of cancer, 2015. 136(2): p. 487-490.

7. Chey, W.D., et al., ACG clinical guideline: treatment of Helicobacter pylori infection. Official journal of the American College of Gastroenterology| ACG, 2017. 112(2): p. 212-239.

8. Fauci, A., D. Kasper, and D. Longo, Harrison's Principles of Internal Medicine Vol 11. 2008.

9. Gene, E., et al., Triple vs. quadruple therapy for treating Helicobacter pylori infection: a meta-analysis. Alimentary pharmacology \& therapeutics, 2003. 17(9): p. 1137-1143.

10. Hoffman, J.S. and D.R. Cave, Treatment of Helicobacter pylori. Current opinion in gastroenterology, 2001. 17(1): p. 30-34.

11. Zullo, A., et al., The sequential therapy regimen for Helicobacter pylori eradication: a pooled-data analysis. Gut, 2007. 56(10): p. 1353-1357.

12. Axon, A. and P. Moayyedi, Eradication of Helicobacter pylori: omeprazole in combination with antibiotics. Scandinavian Journal of Gastroenterology, 1996. 31(sup215): p. 82-89.

13. Misiewicz, J., et al., One week triple therapy for Helicobacter pylori: a multicentre comparative study. Gut, 1997. 41(6): p. 735-739.

14. Zardast, M., et al., Assessment of antibacterial effect of garlic in patients infected with Helicobacter pylori using urease breath test. Avicenna journal of phytomedicine, 2016. 6(5): p. 495. 
15. Katelaris, P.H., et al., A randomized comparison of quadruple and triple therapies for Helicobacter pylori eradication: The QUADRATE Study. Gastroenterology, 2002. 123(6): p. 1763-1769.

16. Malfertheiner, P., et al., Management of Helicobacter pylori infection-the Maastricht IV/Florence consensus report. Gut, 2012. 61(5): p. 646-664.

17. McColl, K.E., Helicobacter pylori infection. New England Journal of Medicine, 2010. 362(17): p. 1597-1604.

18. Meyer, J.M., et al., Risk factors for Helicobacter pylori resistance in the United States: the surveillance of H. pylori antimicrobial resistance partnership (SHARP) study, 1993-1999. Annals of internal medicine, 2002. 136(1): p. 13-24.

19. Shoeibi, S., et al., Comparative study on anti-Helicobacter pylori effects of licorice roots collected from different regions of Iran. Journal of Medicinal Plants, 2010. 9(36): p. 43-214.

20. Lee, S.-A., et al., Original article effect of diet and Helicobacter pylori infection to the risk of early gastric cancer. Journal of epidemiology, 2003. 13(3): p. 162-168.

21. Hajiaghamohammadi, A., et al., Effect of adding garlic extract to anti-helicobacter pylori treatment. Journal of Inflammatory Disease, 2015. 19(1): p. 11-16.

22. Fleischauer, A.T., C. Poole, and L. Arab, Garlic consumption and cancer prevention: meta-analyses of colorectal and stomach cancers. The American journal of clinical nutrition, 2000. 72(4): p. 10471052.

23. McNulty, C.A., et al., A pilot study to determine the effectiveness of garlic oil capsules in the treatment of dyspeptic patients with Helicobacter pylori. Helicobacter, 2001. 6(3): p. 249-253.

24. Fakharian, T. and L. Omidvar, The Effect of Green Tea (Camellia sinensis) on Eradication of Helicobacter Pylori Infection in Patients Afflicted in Birjand. Journal of Birjand University of Medical Sciences, 2018. 25(3): p. 172-180.

25. Rahimian, G., et al., Comparing the combined effect of garlic and mint extract with metronidazole in helicobacter pylori treatment. Iranian Journal of Pharmaceutical Sciences, 2013. 9(3).

26. Matsubara, S., et al., Suppression of Helicobacter pylori-induced gastritis by green tea extract in Mongolian gerbils. Biochemical and biophysical research communications, 2003. 310(3): p. 715719.

27. Latio, L.S.Y., et al., Economic burden of the persistent morbidity of nodding syndrome on caregivers in affected households in Northern Uganda. PloS one, 2020. 15(9): p. e0238643.

28. Mojahedian, M.M., et al., Estimating the cost of illness of prostate cancer in Iran. Clinical therapeutics, 2019. 41(1): p. 50-58.

29. World Bank. PPP conversion factor, private consumption (LCU per international \$) US: The World Bank. ExRates/rates_fa.aspx;; Available from: http://www.cbi.ir/.

30. Kahn, J., et al., Thresholds for the cost-effectiveness of interventions: Alternative approaches. 2015.

31. Nagata, Y., et al., Successful eradication of helicobacter pylori with a herbal medicine, goshuyuto (Wu Zhu Yu tang), plus rabeprazole after failure of triplet therapy with vonoprazan: a report of three 
cases. Journal of digestive diseases, 2018. 19(7): p. 439-442.

32. Iran - GDP per capita. Available from: https://fa.tradingeconomics.com/iran/gdp-per-capita

33. Sancar, M., et al., Pharmacoeconomic comparison of Helicobacter pylori eradication regimens. Pharmacy World and Science, 2006. 28(4): p. 207-214.

34. Yousef-Nezhad, H. and N. Hejazi, Anti-Bacterial Properties of Herbs against Helicobacter Pylori Infection: A Review. International Journal of Nutrition Sciences, 2017. 2(3): p. 126-133.

35. Bokaeian, M. and Z. Bameri, In vitro antibacterial properties of aqueous garlic extract (AEG) against multidrug-resistant enterococci. Zahedan J Res Med Sci, 2013. 15: p. 43-49.

36. Ma, J.-L., et al., Fifteen-year effects of Helicobacter pylori, garlic, and vitamin treatments on gastric cancer incidence and mortality. Journal of the National Cancer Institute, 2012. 104(6): p. 488-492.

37. You, W.-c., et al., Randomized double-blind factorial trial of three treatments to reduce the prevalence of precancerous gastric lesions. Journal of the National Cancer Institute, 2006. 98(14): p. 974-983.

38. Kaviani, M.J., et al., Various durations of a standard regimen (amoxycillin, metronidazole, colloidal bismuth sub-citrate for 2 weeks or with additional ranitidine for 1 or 2 weeks) on eradication of Helicobacter pylori in Iranian peptic ulcer patients. A randomized controlled trial. European journal of gastroenterology \& hepatology, 2001. 13(8): p. 915-919.

39. Nijevitch, A.A., et al., Nifuratel-containing initial anti-Helicobacter pylori triple therapy in children. Helicobacter, 2007. 12(2): p. 132-135.

40. Hojo, M., et al., Pooled analysis on the efficacy of the second-line treatment regimens for Helicobacter pylori infection. Scandinavian journal of gastroenterology, 2001. 36(7): p. 690-700.

41. Tiren, U., B. Sandstedt, and Y. Finkel, Helicobacter pylori gastritis in children: efficacy of 2 weeks of treatment with clarithromycin, amoxicillin and omeprazole. Acta Paediatrica, 1999. 88(2): p. 166168.

42. Graham, D.Y., S.-Y. Anderson, and T. Lang, Garlic or jalapeno peppers for treatment of Helicobacter pylori infection. The American journal of gastroenterology, 1999. 94(5): p. 1200-1202.

43. limuro, M., et al., Suppressive effects of garlic extract on Helicobacter pylori-induced gastritis in Mongolian gerbils. Cancer letters, 2002. 187(1-2): p. 61-68.

44. Yassibas, E., P. Arslan, and S. Yalcin, Evaluation of dietary and life-style habits of patients with gastric cancer: a case-control study in Turkey. 2012.

45. Jonkers, D., et al., Antibacterial effect of garlic and omeprazole on Helicobacter pylori. Journal of Antimicrobial Chemotherapy, 1999. 43(6): p. 837-839.

46. Mabe, K., et al., In vitro and in vivo activities of tea catechins against Helicobacter pylori. Antimicrobial agents and chemotherapy, 1999. 43(7): p. 1788-1791.

47. O'Gara, E.A., et al., The effect of simulated gastric environments on the anti-Helicobacter activity of garlic oil. Journal of applied microbiology, 2008. 104(5): p. 1324-1331.

48. O'Gara, E.A., D.J. Hill, and D.J. Maslin, Activities of garlic oil, garlic powder, and their diallyl constituents against Helicobacter pylori. Applied and environmental microbiology, 2000. 66(5): 
p. 2269-2273.

\section{Figures}

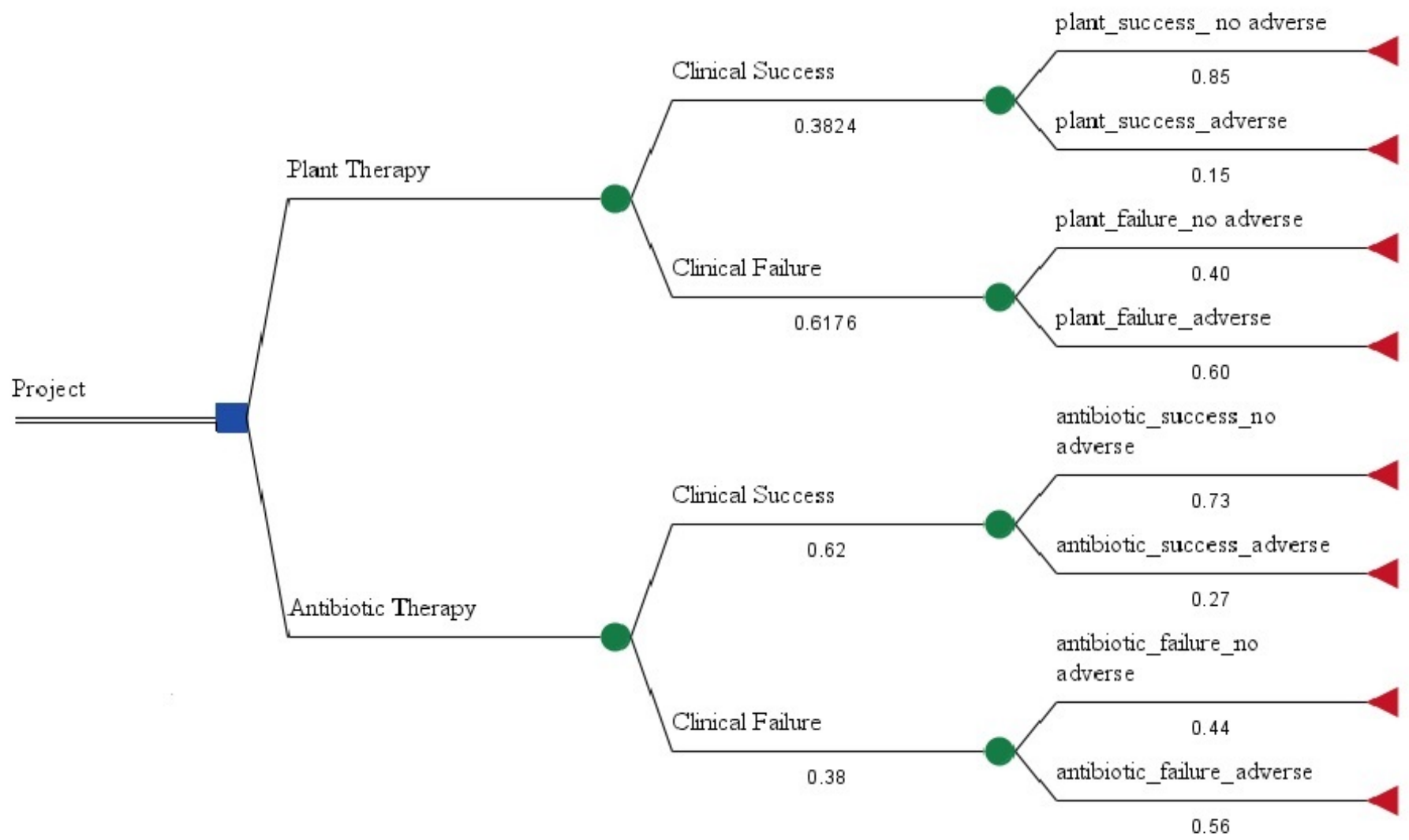

\section{Figure 1}

Schematic diagram of the decision tree structure to compare two plant and antibiotic treatments in patients with Helicobacter pylori infection 


\section{Cost-Effectiveness Analysis}

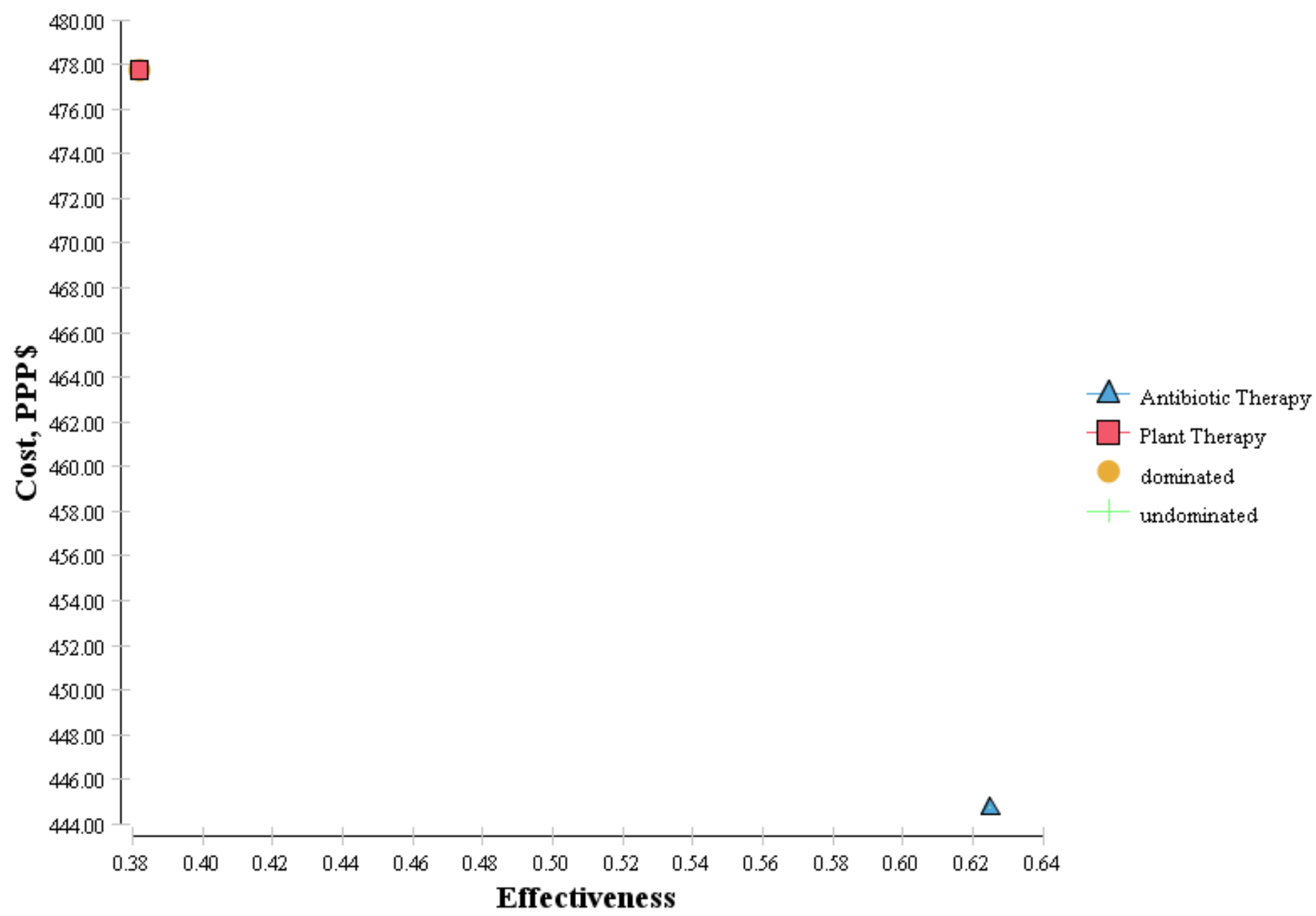

Figure 2

A cost-effectiveness Analysis for the plant and antibiotic treatments in patients with Helicobacter pylori infection 


\section{Tornado Analysis (ICER)}

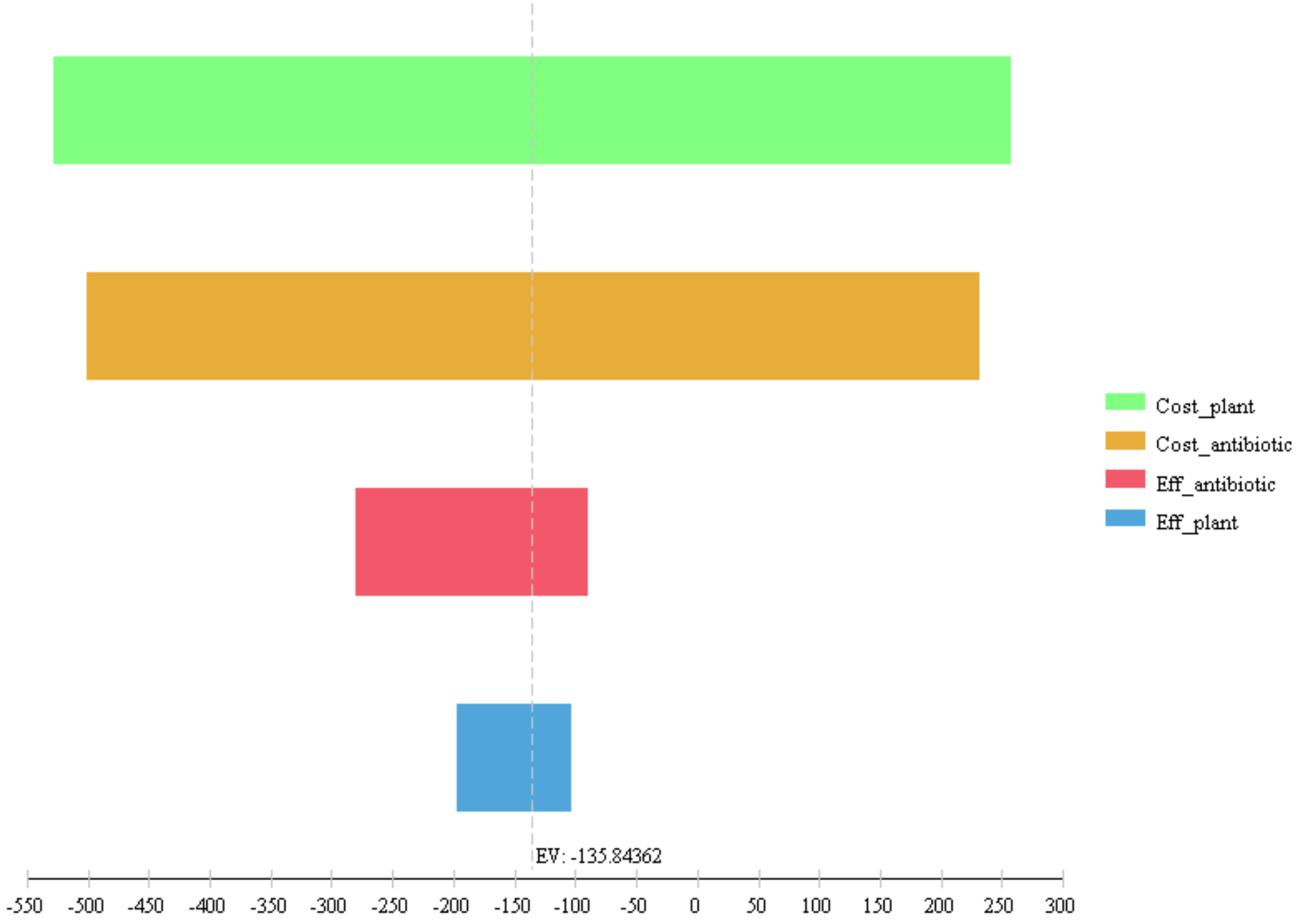

\section{Figure 3}

Tornado diagram for the cost-effectiveness of plant and antibiotic treatments in patients with Helicobacter pylori infection 